\title{
The ring current: a short biography
}

\author{
A. Egeland ${ }^{1}$ and W. J. Burke ${ }^{2}$ \\ ${ }^{1}$ Department of Physics, University of Oslo, P.O. Box 1048, Blindern, 0316 Oslo, Norway \\ ${ }^{2}$ Boston College, Institute for Scientific Research, Chestnut Hill, MA, USA \\ Correspondence to: A. Egeland (alv.egeland@ fys.uio.no)
}

Received: 27 March 2012 - Revised: 26 June 2012 - Accepted: 3 July 2012 - Published: 6 August 2012

\begin{abstract}
The "ring current" grows in the inner magnetosphere during magnetic storms and contributes significantly to characteristic perturbations to the Earth's field observed at low-latitudes. This paper outlines how understanding of the ring current evolved during the half-century intervals before and after humans gained direct access to space. Its existence was first postulated in 1910 by Carl Størmer to explain the locations and equatorward migrations of aurorae under stormtime conditions. In 1917 Adolf Schmidt applied Størmer's ring-current hypothesis to explain the observed negative perturbations in the Earth's magnetic field. More than another decade would pass before Sydney Chapman and Vicenzo Ferraro argued for its necessity to explain magnetic signatures observed during the main phases of storms. Both the Størmer and Chapman-Ferraro models had difficulties explaining how solar particles entered and propagated in the magnetosphere to form the ring current. During the early 1950s Hannes Alfvén correctly argued that the ring current was a collective plasma effect, but failed to explain particle entry. The discovery of a weak but persistent interplanetary magnetic field embedded in a continuous solar wind provided James Dungey with sufficient evidence to devise the magnetic merging-reconnection model now regarded as the basis for understanding magnetospheric and auroral activity. In the mid-1960s Louis Frank showed that ions in the newly discovered plasma sheet had the energy spectral characteristics needed to explain the ring current's origin. The introduction of ion mass spectrometers on space missions during the 1970s revealed that $\mathrm{O}^{+}$ions from the ionosphere contribute large fractions of the ring current's energy content. Precisely how cold $\mathrm{O}^{+}$ions in the ionosphere are accelerated to ring-current energies still challenges scientific understanding.
\end{abstract}

\section{Introduction}

This paper presents a historical overview of how the concept of a stormtime ring of electric current encircling the Earth evolved over roughly five decades before and after humans gained direct access to space. It is aimed at a general audience interested in the long-term growth of scientific understanding rather than exclusively towards experts regarding the physics of our space environment. We hope that the latter may also profit reading about how the ring-current concept developed via inferences derived from ground-based measurements. They will profit reading scientific reviews by Kertz (1958), Smith (1963), Daglis et al. (1999a) and Stern (2005), from which we gratefully acknowledge having learned much.
The phrase "ring current" conjures up images that are all connected with wide-spread and repeatable patterns of geomagnetic activity called "magnetic storms", a name coined in 1808 by Alexander von Humboldt (1769-1859). At low magnetic latitudes the Earth's field mainly points northward. As illustrated in Fig. 1, most storms begin with rapid increases in the field strength measured at low latitudes called "sudden storm commencements" (SSC). The perturbation field $\Delta B_{\mathrm{N}-\mathrm{S}}$ may remain northward for an hour or more (initial phase) or, as in the present case, quickly begin to turn along a downward trajectory for the next six to twelve hours, called the "main phase". Eventually, the perturbations weaken and over several days of "recovery", the magnetic field returns to prestorm values. Since all magnetic fields are products of electrical currents, it would seem likely that the existence and life stages of a westward ring current in space above Earth was 
first deduced to explain the southward perturbations observed during the main and recovery phases. This surmise is nearly true. Between 1916 and 1930 the ring current was rediscovered several times for just this reason. However, the first documented argument for the development of an extra-terrestrial ring current was suggested in 1910 by Carl Størmer (18741957), Professor of Pure Mathematics at the University of Christiania (now Oslo), for reasons that had little to do directly with magnetic-perturbation traces like those shown in Fig. 1. Rather, Størmer postulated episodic developments of a ring current to explain why it had been possible for him to see auroral forms in the sky above southern Norway. To understand why Størmer would consider this ring-current postulate, we review briefly what was known about geomagnetism and the aurora before and in the first decade of the 20th century.

For centuries the magnetic properties of lodestones were known and used as navigational aids. However, it was not until 1600 that William Gilbert (1544-1603) conducted the first systematic investigation of magnetism and published its results in De Magnete. Gilbert's most important conclusion was that "the Earth itself is a large magnet" whose strength is greatest at the poles. He also noted that the magnetic poles are displaced a few degrees from the geographic poles and recognized that the Earth's field changes continually, sometimes violently. More than a century would pass before Edmond Halley (1656-1742) compared the characteristics of magnetic-field directions at different parts of the Earth and speculated about the number of magnetic poles that were needed to account for the observed variations. His speculations included the possibilities that the Earth was a hollow sphere and perhaps gaseous emanations from its interior were responsible for the aurora (Halley, 1692).

In retrospect the 18th and 19th centuries were watersheds of discovery in the field of electromagnetics that made possible the technological advances of the 20th century that we now almost take for granted. In London, George Graham (1675-1751), a watchmaker by profession, developed new systematic methods to monitor variations in the Earth's magnetic field that underlie present-day magnetic indices. Precise measurements of diurnal magnetic deflections mark the first human encounter with what we now call the solar quiet (Sq) system of ionospheric currents (Graham, 1724). A comparison of his own magnetic declination measurements with those of Halley revealed that the Earth's magnetic field is undergoing long-term variations (Graham, 1748). In 1741 Anders Celsius (1701-1744) and Olaf Peter Hiorter (16961750), at the University of Uppsala, noted that the orientation of suspended magnetic needles tilted to the left or right of the magnetic pole's direction whenever aurorae were visible. Because perturbations to compass directions posed serious threats to navigation, their observation had serious practical consequences. Still, they were unable to explain why auroral displays should affect compass directions. A century and a half would pass before Kristian Birkeland (1867-1917)

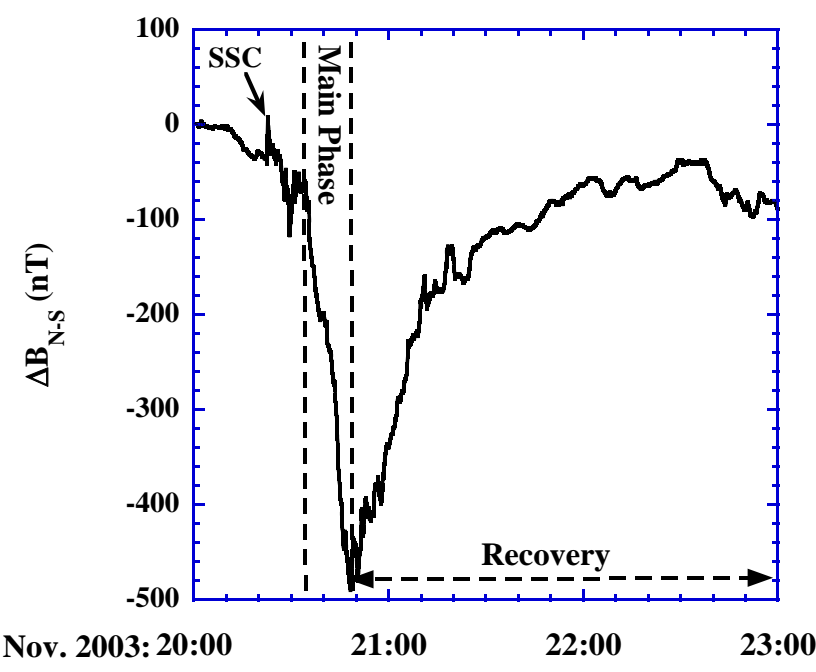

Figure 1. Compilation of north-south magnetic perturbations $\left(\Delta B_{\mathrm{N}-\mathrm{S}}\right)$ in nano-Tesla as observed between 20 and 23 November 2003 at six low-latitude stations during a very large magnetic storm. Times of the SSC (near mid-day on 20 November), the main and recovery phases are indicated for reference (Iyemori, 1990).

offered the first scientifically correct explanation of this relationship. He argued that fluctuations of the geomagnetic field provide critical information about the electrical currents flowing in the near-Earth space environment and that they are related to activity on the Sun (Birkeland, 1908).

Hans Christian Ørsted (1777-1851) demonstrated that the orientation of magnetic needles also changed when electric currents flowed in nearby wires. Ørsted published the discovery that electric currents cause magnetic disturbances in 1820. About a decade later Michael Faraday (1791-1867) demonstrated that time-varying magnetic fields induce electric currents. In 1865 James Clerk Maxwell (1831-1879) unified the work of Ørsted and Faraday in the fundamental laws of electromagnetism.

In 1812 Christofer Hansteen (1774-1873) entered a Europe-wide competition to answer the question raised by Halley (1692): "Can we explain the Earth's magnetic phenomena with a single magnetic axis, or must several axes be assumed?" Hansteen won the competition with a dissertation Untersuchung über den Magnetismus der Erde that concluded existing declination measurements can only be explained if the Earth's magnetic field has four poles. He would later be appointed the first professor of science-applied mathematics, at the recently founded University of Christiania. Between 1828 and 1830 Hansteen led an expedition across Siberia to China looking for a second pole in the Northern Hemisphere. Although Hansteen failed to locate another pole, the magnetic map he developed during the expedition was of considerable use to Carl Friedrich Gauss (17771855). Systematic recordings of simultaneous magnetic field variations began in 1834, when he deployed magnetometers 


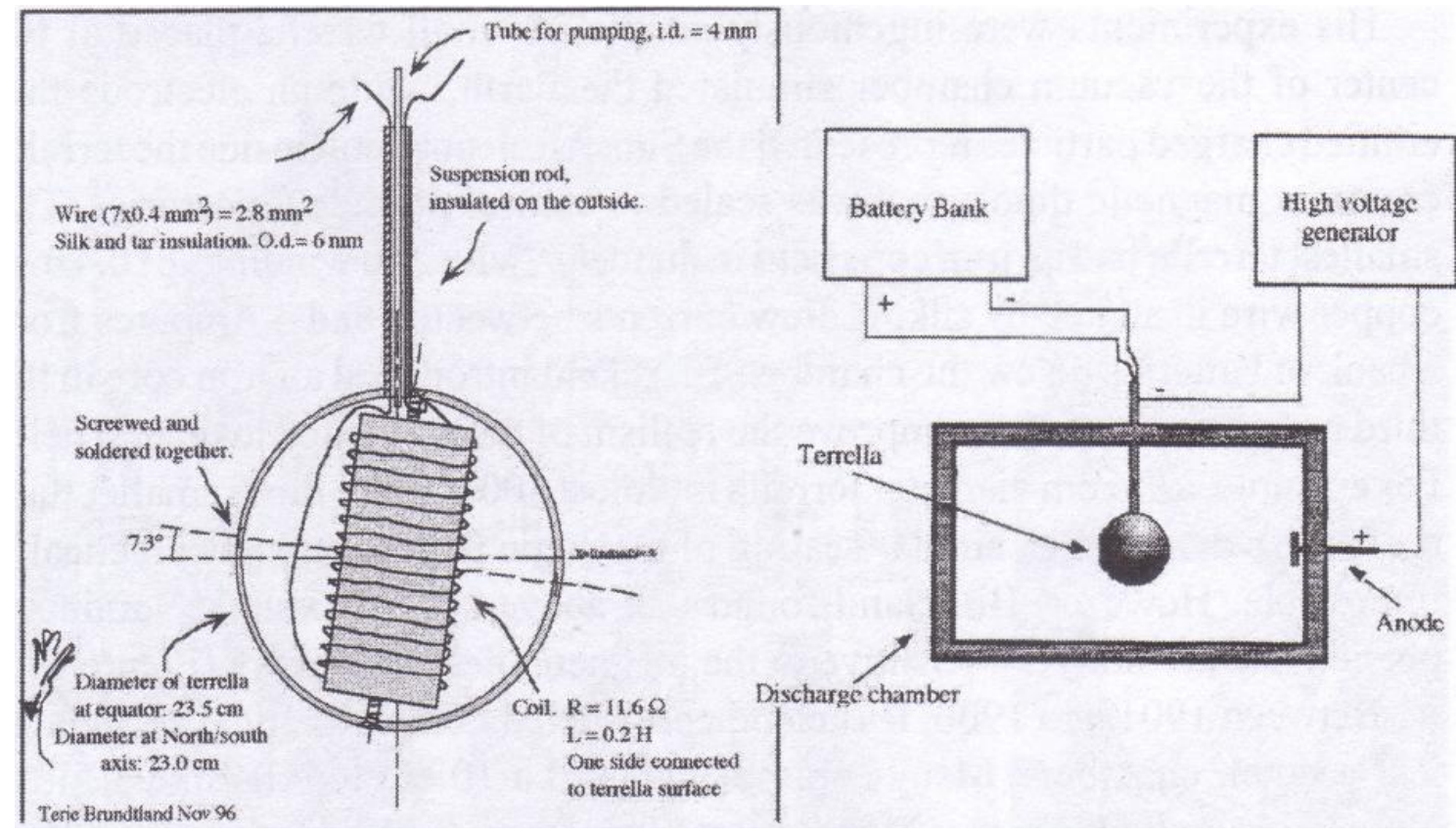

Figure 2. Schematics showing the principles underlying terrella experiments. Brundtland (1997) provides detailed technical drawings showing the terrella and the vacuum chamber to illustrate how dipolar magnetic fields were produced.

of the Göttingen Magnetic Union at stations around Europe. Gauss (1839) initiated the modern study of geomagnetism by applying the gravitation potential formalism of Laplace to the Earth's field. He argued that magnetic fields seen on the ground have sources both inside $\left(B_{\text {int }}\right)$ and outside $\left(B_{\text {ext }}\right)$ the Earth, then demonstrated harmonic analysis techniques to separate them. He concluded that $B_{\text {int }}$ was due to a large, permanent field from inside the Earth that varies from approximately 30000 to 60000 nano-Tesla (nT) between the magnetic equator and the poles. This field is well approximated as a dipole whose axis tilts about $11^{\circ}$ to the Earth's rotational axis. Currents flowing above the Earth are responsible for the much weaker $B_{\text {ext }}$, which varies from about $50 \mathrm{nT}$ on quiet days to more than $3000 \mathrm{nT}$ during magnetic storms. The largest variations occur at high latitudes. Throughout Gauss's life their causes remained hidden.

Although the auroral problem was not of central interest to Hansteen, in 1825 he surmised: "The northern lights must be part of a shining ring, with a diameter of about 4,000 kilometers, of which each observer sees his own segment. This leads us to suppose that there must be some connection between the aurora and the Earth's magnetism." In a letter to Gauss dated 22 July 1841, Hansteen discussed the observed geomagnetic variations in the horizontal component observed during his visit at Göttingen in September 1839. This coincided with an intense red aurora over northern Germany. Kertz (1958) pointed out that this was probably the first significant observation of a ring-current effect.

In Das Polarlicht, Fritz (1881) demonstrated that the most probable locations for observing auroral displays lie between $20^{\circ}$ and $25^{\circ}$ in latitude from the magnetic poles. For later reference we note that Christiania/Oslo is located about $33^{\circ}$ from the north magnetic pole. However, northern Norway is ideally located for observing auroral activity. In the winters of 1899-1900 and 1902-1903, Kristian Birkeland organized expeditions to northern Norway, Iceland, Svalbard and Russian Novaya Zemlya to study the aurorae and associated magnetic perturbations.

During the two campaigns Birkeland (1908) became convinced that the Sun was the only energy source large enough to explain auroral and magnetometer measurements. To confirm these conjectures, Birkeland devised laboratory simulations called terrella experiments, shown schematically in Fig. 2. Terrellas consisted of magnetized spheres located at the centers of relatively large vacuum chambers. To simulate the Earth's space environment, magnetic fields approximated those of dipoles. Cathode ray guns, similar to those found in early television sets, were located near the chamber walls to emulate electron sources on the Sun. The spheres were coated with phosphorescent paint to identify where the electrons impacted the surface. As seen on the left side of Fig. 3, when the cathode ray guns were turned on, visible light appeared on the sphere's surface in rings around the magnetic poles. The ring's radius was eerily consistent with Fritz's description of the auroral zone. These results were fully reproducible over several generations of ever more sophisticated terrellas. Still Birkeland regarded them as suggestive that the Sun was the direct source of auroral stimulation rather than compelling. To proceed he sought mathematical calculations of trajectories allowed to energetically charged particles as 


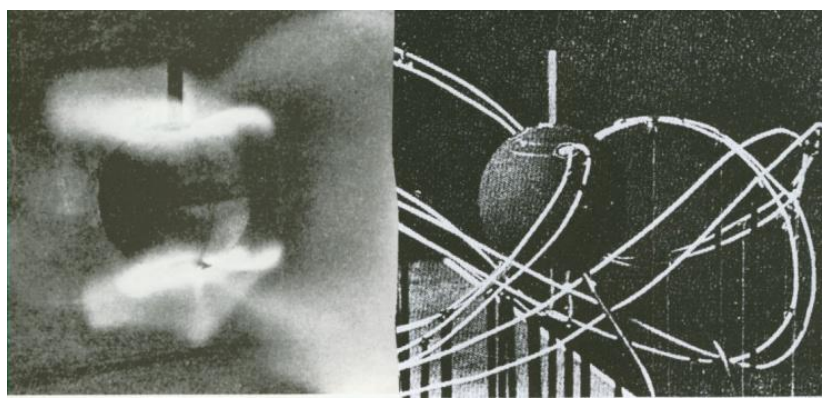

Figure 3. Left: Birkeland's terrella with the auroral zones simulated as rings of bright optical emissions around both poles when the magnetized sphere is bombarded with energetic electrons. Right: Størmer trajectories of energetic electrons that impact the Earth's upper atmosphere. Agreement between Birkeland's laboratory simulations and Størmer's calculations is excellent.

they entered and moved in the field of a magnetic dipole, a problem that had never been addressed. When Carl Størmer returned to Christiania in 1900 from post-graduate studies in France, Birkeland saw an opportunity to obtain these calculations.

\section{Invention of the ring current}

This section covers the roughly $50-y r$ period between the time Størmer first addressed auroral problems and postulated the ring current's existence and the direct access to measurements in space became available. Størmer identified the beginning of his involvement in auroral physics as the day in the autumn of 1902 when he visited Kristian Birkeland's terrella laboratory.

On being appointed Professor of Pure Mathematics in 1903, Størmer became one of Birkeland's academic colleagues. In their discussions Birkeland conveyed his belief that auroral research was limited by constricting ideas and primitive instrumentation. He showed Størmer his terrella simulations of aurorae and pointed out that the trajectories of charged particles reaching the Earth from the Sun were a problem awaiting quantitative solution. Effectively he challenged Størmer to apply his mathematical skills to quantify charged particle motions in realistic magnetic geometries. Thereby Birkeland sparked Størmer’s interest, leading him to develop powerful new methods for calculating trajectories allowed and forbidden to energetic particles in magnetic dipoles. In response Størmer began a journey developing numerical integration techniques on which he and his graduate students spent more than $30000 \mathrm{~h}$ calculating trajectories.

Henri Poincaré (1854-1913), a mentor of both Birkeland and Størmer, had already calculated the trajectories of charged particles in a monopole magnetic field. However, in nature magnetic fields appear as dipoles or quadrupoles and never as monopoles. Størmer easily worked out the general equations of motion for charged particles in a dipolar magnetic field, but soon realized that his equations were not amenable to analytic solutions. Rather it would be necessary to perform numerical integrations that follow the trajectories of individual electrons, step by tedious, time-consuming step. In his first paper on electron trajectories, Størmer (1904) wrote: "Birkeland has described artificial aurorae produced in his terrella laboratory. From a theoretical viewpoint there exists an especially interesting problem, namely solving the equations of motion of an electron in a magnetic field. ... The importance of the solution to this problem for Birkeland's theory is very clear." Interested readers are directed to Part II, Chapters 1-4 in Størmer's book The Polar Aurora (1955) for a full exposition of his method.

Over time Størmer became concerned that perhaps he had developed mathematical descriptions of electrons in terrella devices rather than auroral particles in nature. Occasionally, Størmer had actually seen aurorae overhead and south of Christiania, well south of Fritz's auroral zone. Neither the terrella experiments nor his mathematical analysis of allowed trajectories could explain auroral electrons reaching Christiania's latitude. He felt that his representation of the Earth's magnetic field must be in error during these episodes. Observations of faint glows in the terrella's equatorial plane from electrons that bent toward the nightside offered a clue.

In seven long papers with the same title Sur les trajectoires des corpucules électrisés dans l'espace sous l'action du magnétisme terrestre avec application aux aurores boréales, Størmer $(1911,1912)$ considered the consequences of a ring of current forming in the equatorial plane on the Earth's magnetic environment and on consequent electron trajectories. In what he referred to as his "Geneva papers", Størmer showed mathematically how the Earth's field is modified as such a "ring current" intensifies. His equations determined the angular distance of the auroral zone from the magnetic axis. Summarizing this work on page 345 of The Polar Aurora, Størmer wrote: "If we assume the permanent existence of a circular stream of only $30 n T$ in the geomagnetic equatorial plane of the Earth, with center in the centre of the latter, the effect of such a stream is sufficient to draw the aurora belt down from its theoretical situation to the actual distance of about 23 degrees from the geomagnetic axis pole." If however, the ring current produced a $300 \mathrm{nT}$ perturbation on the ground, his theoretical analysis predicted that the auroral zone should shift equatorward to Christiania's latitude $33^{\circ}$ from the magnetic pole.

Størmer's suggestion was neither immediately appreciated nor completely ignored. Röstadt (1928) and Nagata (1950) studied the systematics of the auroral zone's equatorward migration as magnetic activity increased. In the late 1920s, with consultation from Størmer, Ernst Brüche (1900-1985) recreated a terrella at the University of Leipzig. To his terrella's capabilities Brüche added a controlled circular electric current in the simulation's equatorial plane. Figure 4 shows examples of auroral zone locations produced in experiments with the ring current off (left) and on (right). A 

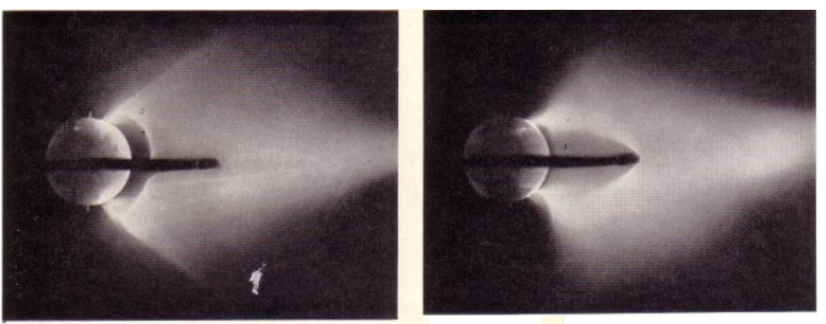

Figure 4. Ernst Brüche's version of Birkeland's terrella simulations with electric currents added. The current in the equator plane is turned off/on in the left/right picture. They illustrate that the ring current moves the auroral zones toward the magnetic equator (Brüche, 1930).

ring-current-induced equatorward migration of the auroral zone is clearly evident in comparisons of the two examples. In publishing his results Brüche (1930) explicitly referenced Størmer's work in the paper's title. In The Polar Aurora's Figures 162-164, Størmer favorably compared his calculations with observed thread-like electron trajectories photographed in Brüche's terrella experiments.

It is not uncommon in the development of scientific understanding that a new idea introduced to explain one phenomenon has applications in other areas. Maxwell's unification of electricity and magnetism is probably the best known example. Adolf Schmidt (1860-1944), the director of the Potsdam Magnetic Observatory, found an opportunity to apply Størmer's idea to explain the negative perturbations observed during the main phase of storms. He did not explain how a ring current might come to be. Rather he adapted the spherical harmonic technique introduced by Gauss to show that such a current produced magnetic perturbations consistent with observations at the Earth's surface (Schmidt, 1917). He pointed out that where Størmer required a $300 \mathrm{nT}$ perturbation at the equator to move the auroral zone southward by $10^{\circ}$, Schmidt's calculation indicated that only a $200 \mathrm{nT}$ decrease in $\Delta B_{\mathrm{N}-\mathrm{S}}$ was needed at the latitude of Potsdam to accomplish the same auroral migration. Schmidt explicitly admitted that causes of the ring current's development exceeded the bounds of contemporary understanding.

After graduating from Cambridge University in 1910, Sydney Chapman (1888-1970) accepted a senior assistant position at the Greenwich Observatory. Its director Sir Frank Dyson (1868-1939) encouraged him to analyze data acquired by the observatory's magnetometers. Chapman (1919) focused on tidal effects of the Sun and Moon on perturbations to ionospheric currents seen during quiet days. It was not until 1918 that he published his first study of magnetic storms. Based largely on the works of Birkeland and Størmer, he treated electrons from the Sun as the source of storms. Lindemann (1887-1957) in 1919, pointed out that space charge effects would quickly limit such emissions, but suggested that a stream of ions and electrons might overcome this difficulty.

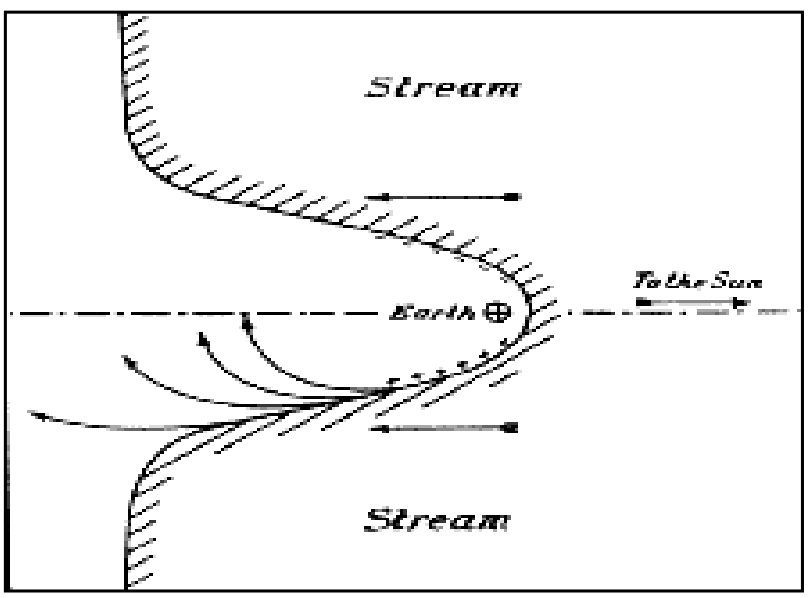

Figure 5. The formation of the Chapman-Ferraro cavity. Arrows indicate paths of ions and electrons that account for the ring current's formation (Chapman and Ferraro, 1933).

In the late 1920s Chapman joined forces with a young graduate assistant, Vicenzo Ferraro (1907-1974), to investigate the interactions of an electrically neutral stream of charged particles, emitted from the Sun at the times of solar flares. Chapman and Ferraro $(1931,1932)$ argued that as the stream advances into the Earth's magnetic field, a sheet of electric current forms. This current compresses the field between itself and the Earth and exactly cancels the magnetic field between itself and the Sun. This process continues to compress the Earth's field until the magnetic pressure balances the pressure exerted by the oncoming stream of solar electrons and protons. As illustrated in Fig. 5, the compressed terrestrial magnetic field carves out a cavity in the solar stream, later called the magnetosphere (Gold, 1959). Using what they regarded as reasonable estimates of the stream's speed and density, Chapman and Ferraro calculated that the distance between the center of the Earth and the sub-solar stand-off distance was about 10 Earth radii $\left(R_{\mathrm{E}}\right)$. At the Earth's surface the interaction would appear as a sudden increase in field strength (the SSC) that could last for several hours (the initial phase). In the 1930s scientists had no convincing evidence indicating that ionized gas continuously streams from the Sun.

Having passed the hurdle of explaining storm initiation, they turned their attention to the more difficult problem of modeling the physics of a storm's main phase (Chapman and Ferraro, 1933). Nearly four decades later Ferraro tried to capture their thinking at the time and evaluate their main-phase efforts:

"Some months previously we had again considered the Størmer-Schmidt hypothesis of the ring current, and had shown that for mechanical equilibrium the current had to be westward. This, we argued, would produce the necessary diminution in the earth's magnetic field associated with the main 
phase of a magnetic storm. We showed that to produce a diminution of, say, $50 \gamma(1 \gamma=1 \mathrm{nT})$ during a moderate storm, the mean radius of the ring had to be a few Earth radii.

We had not, however, indicated how such a ring current could be formed. We supposed that the ions and electrons would circulate together around the earth in large circles. When the first phase of the theory of magnetic storms was developed, we showed that the wall of the hollow facing the morning side of the earth would be positively charged, and that the wall facing the evening side of the earth would be negatively charged, because of the tendency of the positive and negative charges to be deflected eastward and westward respectively. Such charges would be unstable, and we imagined that the ring current could perhaps be formed by charges escaping from the walls of the hollow and bridging the gap.

Our ideas about the ring current, unlike those relating to the first phase, were not based on hydromagnetic concepts, and our theory of the main phase is today generally considered unacceptable" (Ferraro, 1970).

In the early 1950s while writing The Polar Aurora, Størmer invited Hannes Alfvén (1908-1995) to provide an alternate explanation of the ring-current formation based on his developing hydromagnetic concepts. Taking Chapman's ionized, outward-moving solar stream as his starting point, Alfvén argued that the stream crosses magnetic field lines extending back to the Sun, thus inducing an electric field within the stream. As illustrated in Fig. 6, he argued that the electric field allowed solar stream ions and electrons to pass into the magnetic cavity in the flow. Within the cavity the Earth's magnetic field is dominant. Here Alfvén distinguished between the gyro-motion that charged particles undergo in magnetic fields and the motion of the gyro-motion's guiding center. If a charged particle in a magnetic field $\boldsymbol{B}$ is subject to an external force $\boldsymbol{F}$, then the point around which it gyrates moves with a drift velocity $\mathbf{V}_{\mathrm{D}}$ that is perpendicular to both $\boldsymbol{B}$ and $\boldsymbol{F}$ and has a magnitude $F / q B$, where $q$ represents the particle's charge. Since the force exerted by electric fields is $\boldsymbol{q E}$, electrons and positive ions drift with the same velocity and carry no current. However, as electrons and ions encounter gradients in the magnetic Earth's field, they are subject to eastward and westward drifts, respectively. The natural consequence is a westward ring current. Unlike Størmer and Chapman-Ferraro who envisaged individual particles encircling the Earth, Alfvén argued that it was the aggregate of guiding center motions that gave rise to the ring current and the main-phase perturbations seen at the ground. He also showed that the particles are energized by the electric field as they drift close to Earth and that fieldaligned currents also form to couple the ring current to the auroral ionosphere. Prudently, Størmer deferred comment, leaving evaluations of Alfvén's thought to future historians. For its time the model was indeed a brilliant tour de force. For solar ions and electrons to penetrate close enough to the Earth to provide the ring current, Alfvén was required to have the interplanetary electric field in the dusk-to-dawn direction. Thus, affected particles pass the Earth from the day- to the nightside. Within a decade space measurements would show that the electric fields responsible for energizing ring-current particles are directed from dawn-to-dusk and, somewhat counter-intuitively, ring-current particles approach Earth from the night- towards the dayside.

Four critical developments occurred during last few years before exploration of Earth's space environment began in earnest, three theoretical and one practical that profoundly influenced space research in the coming decades. Considered in chronological order:

1. Singer (1957) proposed a model of the ring current forming during the main phase of storms that combined Alfvén's guiding-center drifts with Størmer's concept of forbidden regions in the Earth's magnetic field. Without offering a mechanism for gaining access to forbidden regions, Singer argued if they somehow could get in, the ions and electrons would be trapped and their oppositely drifting guiding-center motions would constitute a westward ring of current around the Earth.

2. Parker (1959) argued that gas continually evaporates from the solar corona with enough energy to escape the Sun's gravitational field. He also showed that at a critical distance that depends on coronal conditions, the gas's outward flow can transition from sub- to supersonic flow. This suggested that a super-sonic solar wind was a permanent property of our space environment rather than the sporadic structures envisaged by Chapman and Ferraro (1931).

3. Considering the cases of isotropic equatorial mirroring particles, Dessler and Parker (1959) showed that $\Delta B_{\mathrm{N}-\mathrm{S}}$, the magnetic perturbation observed on the ground, is directly proportional to $E_{\mathrm{RC}}$, the total energy of the ringcurrent particles. Sckopke (1966) demonstrated the validity of this $E_{\mathrm{RC}}$ relationship for all pitch-angle distributions. Stern (2005) provides a simple estimate of what is now called the Dessler-Parker-Sckopke relation by $E_{\mathrm{RC}}($ Joules $) \approx 3.87 \times 10^{13} \times\left|\Delta B_{\mathrm{N}-\mathrm{S}}\right|(\mathrm{nT})$. Dessler and Parker (1959) were also the first to suggest that the decay of the ring current during the recovery phase of the storm is due to charge exchange between energetic protons and cold hydrogen atoms in the geocorona. This gas was known to exist due to its resonant scattering of ultraviolet light from the Sun.

4. As chairman of the International Association of Geomagnetism and Aeronomy's (IAGA) Committee on 

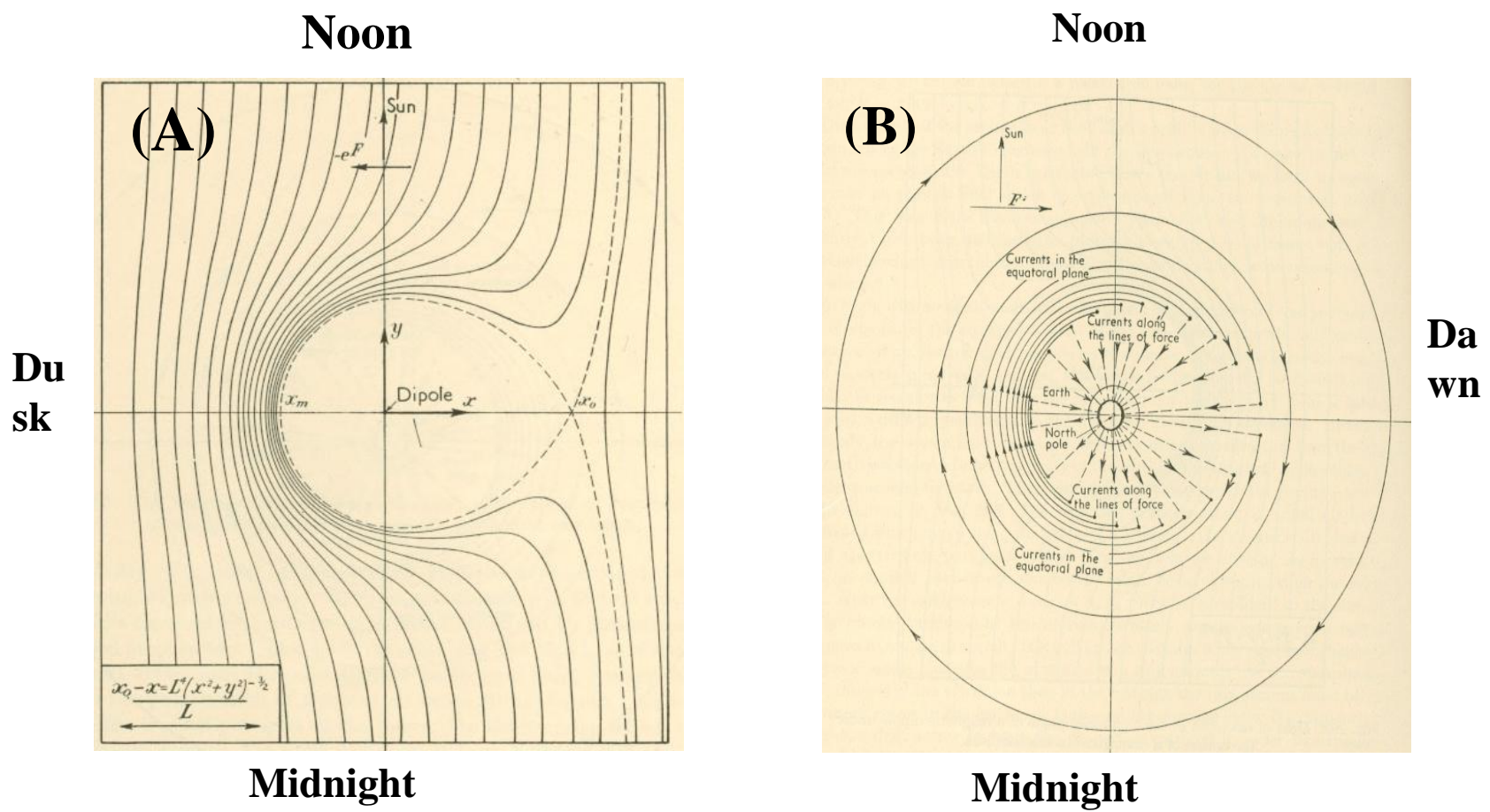

Figure 6. Alfvén's concept of (A) energetic electron drift paths in the equatorial plane of a dipolar magnetic field with a uniform dusk-todawn, and (B) the resultant ring current in the equatorial plane. Note that Alfvén's ring current is highly asymmetric requiring that it close through the auroral ionosphere via magnetic field aligned currents - i.e. Birkeland currents (Størmer, 1955).

Characterization of Magnetic Disturbance during the 1950s, Julius Bartels (1899-1964) championed the development of a magnetic index that monitored ringcurrent variations (Mayaud, 1980). His efforts resulted in the development of two competing methodologies. Kertz $(1958,1964)$ used $\Delta B_{\mathrm{N}-\mathrm{S}}$ perturbations measured at 27 stations at mid- and low-magnetic latitudes to develop an index he called $E_{\mathrm{RC}}$ that characterizes the energy contributions of the equatorial ring current. To minimize contamination from magnetic perturbations produced by the dayside electrojet and the solar quiet (Sq) current system, Kertz opted to use only the data subset acquired on the nightside. Measurements from nightside stations were averaged and reported at a 3-h cadence. Sugiura (1964) argued that dayside contamination could be minimized by using spatial and temporal averages of variations in the horizontal component of the Earth's field observed at four off-equatorial stations that are widely spaced in longitude. The resultant disturbance stormtime index (Dst) is reported at a 1-h cadence. The discovery by Akasofu and Chapman (1964) that the ring current is not uniformly distributed in local time raised serious practical difficulties for implementing Kertz's method. In 1969 IAGA officially sanctioned the use of Dst as a measure of the stormtime ring current. Recently a new index, called Sym H, has been developed, which uses averaged data from 6 stations re- ported at a 1-min cadence (Iyemori, 1990). In most applications Sym $\mathrm{H}$ can be treated as a high-resolution version of Dst, albeit with reduced absolute accuracy (Wanliss and Showalter, 2006). The $\Delta B_{\mathrm{N}-\mathrm{S}}$ trace in Fig. 1 is actually Sym H measured during the November 2003 magnetic storm. Dst and Sym H are regularly published for scientific use by the University of Kyoto's World Data Center.

\section{The ring current in the space age}

The months following the 1957 launch of Sputnik were times of frustration as one Vanguard payload after another failed to achieve orbit. The successful launch of Explorer 1 and discovery of the radiation belts made the wait seem worthwhile (Van Allen and Frank, 1959). Did the presence of trapped, high energy particles indicate the ring current had been immediately found? Simple calculations made it evident that radiation belt particles could not carry sufficient current; they were something new. Soon NASA sent Mariner and Explorer spacecraft towards Venus on trips that demonstrated the permanent presence of Parker's supersonic solar wind (Snyder and Neugebauer, 1964; Neugebauer and Snyder, 1966) and unexpectedly revealed that space was permeated with a weak interplanetary magnetic field (IMF) (Coleman et al., 1960).

To the mind of James Dungey, this new information suggested a plausible explanation of how particles and 


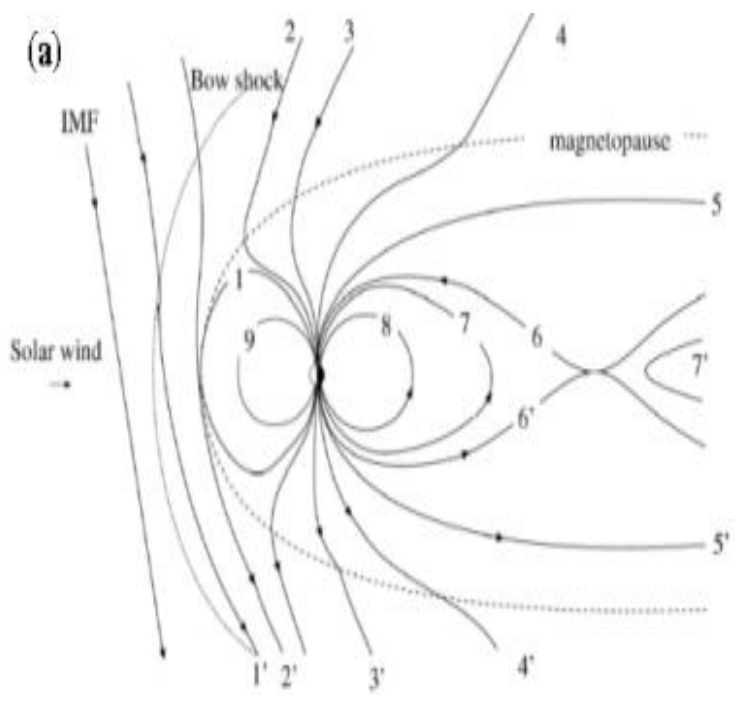

(b)

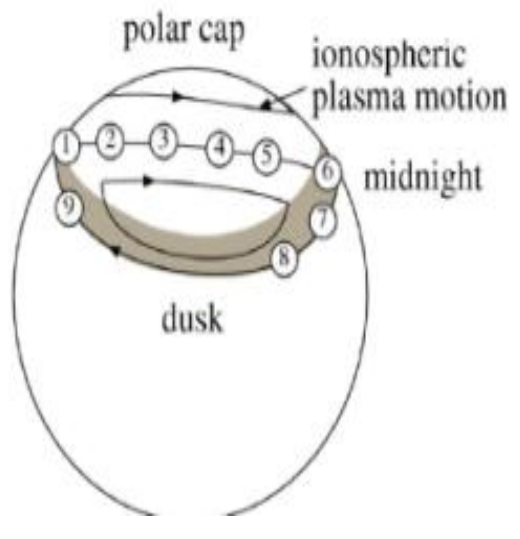

Figure 7. Schematic of Dungey's model as it applies (a) to the magnetosphere and (b) to the high-latitude ionosphere. Numbers 1 through 9 can be viewed as either a snapshot of nine representative field lines in the convection pattern or as the history of a given field line as it passes through the Dungey cycle, anti-sunward across the polar cap and sunward through the auroral (grey) ionosphere (Hughes, 1995).

electromagnetic energy pass from the solar wind into the magnetosphere. As illustrated in Fig. 7a, Dungey envisaged three types of magnetic topology: (1) closed field lines with both feet tied to the Earth, (2) interplanetary field lines with both feet in the solar wind, and (3) open field lines with one foot tied to the Earth and the other to the solar wind. Dungey (1961) pointed out that if the IMF is directed southward as it convects up to the dayside magnetopause, it encounters northward closed field lines. These oppositely directed field lines can merge on the dayside magnetopause to create the third, open-field line typology. These field lines are dragged downstream by the solar wind, and their ionospheric footprints (Fig. 7b) convect from near local noon toward local midnight across the polar cap. Somewhere downstream open field lines of opposite polarity tied to the northern and southern ionosphere come together and reconnect, changing two open field lines into a closed and an interplanetary field line. The newly created closed field line snaps back toward the Earth, while the new interplanetary field line blows away in the expanding solar wind. The footprints return to the dayside through the northern and southern auroral ionosphere (shaded region in Fig. 7b). Dungey used the image of a magnetic donut consisting of closed flux that on the nightside stretched to some as yet undetermined distance; open flux threaded the donut hole stretching beyond the distant reconnection line. The solar-wind-driven interchange between open and closed flux in turn drove a large circulation of plasma and electric currents that flow in the high-latitude ionosphere during magnetic disturbances.

Although Dungey's concept was initially difficult to grasp, bit by bit evidence supporting his point of view accumulated. Magnetometers on Explorers 10, 16 and 33 showed the
Earth's field on the nightside stretching back at least $80 R_{\mathrm{E}}$, with no end in sight. As anticipated in Dungey's model, in the northern half of the magnetotail, the field pointed toward the Earth, and in the southern half away from the Earth (Ness, 1965; Ness et al., 1967). Shatten and Wilcox (1967) provided the first of many reports linking Dungey's predicted onset and cessation of auroral and geomagnetic activity with changes in the polarity of the IMF's north-south component.

Dungey's magnetic merging-reconnection cycle offers a plausible alternative to the concepts of Størmer and Chapman-Ferraro regarding solar-wind particle entry to the magnetosphere. Solar-wind electrons and protons can cross the dayside magnetopause along newly opened flux, then flow freely toward the Earth ( 1 and 2 in Fig. 7a). While some particles precipitate into the dayside ionosphere, most are reflected back along the open field line on which they entered. They flow tailward along open flux (3 through 6 ) before making back-door entries to the closed field line portion of the magnetosphere across reconnection lines in the magnetotail. Subsequently they are further energized while moving earthward into the high magnetic field region (7 and 8), then lose energy as they drift back to the dayside magnetopause (9). The discovery of a permanent plasma sheet confined between the open flux lobes of the magnetotail was consistent with this picture (Bame et al., 1966; Vasyliunas, 1968). The plasma sheet electrons had spectral distributions that closely resembled those measured by sounding rocket experiments above the aurorae. However, establishing a definite source for ring-current particles required adaptations in the sensor technology used to make measurements in space.

At the dawn of the space age, two types of particle sensors were available for immediate use: Geiger counters to 
monitor particles with energies in the mega-electron Volt $(\mathrm{MeV})$ range, and plasma traps sensitive to the properties of very low-energy particles. These sensor types were used to discover the radiation belts and the solar wind, respectively. Early encounters with the plasma sheet showed characteristic energies in the kilo-electron Volt $(\mathrm{keV})$ range. The adopted solution was to develop sensors called electrostatic analyzers (ESAs). Charged particles enter and aperture into a narrow gap between two cylindrical plates that are held at different electric potentials. If the particle has the correct energy, it passes freely through the gap. If its energy is outside a very narrow range, it collides with the inner or outer plate. Particles passing through the gap then impact a specially doped glass tube that generates an avalanche of about a million secondary electrons for every particle impacting the tube (Allen, 1939). By designing an ESA with two parallel sets of plates with controlled potential differences between them, it becomes possible to measure simultaneously the spectra of electrons and ions with energy between a few tens of $\mathrm{eV}$ and several tens of $\mathrm{keV}$.

When the OGO 3 (Orbiting Geophysical Observatory) satellite was launched in June 1966 into a highly elliptical orbit, it carried such an ESA. Within a year a paper published by University of Iowa professor Louis Frank showed that spectral analysis indicated that ring-current protons originated in the plasma sheet (Frank, 1967a, b, 1971). In November 1971 NASA launched the Explorer 45 satellite into an elliptical orbit with a primary mission of detailing the dynamics of the plasmapause and the ring current. During its four-year lifetime, Explorer 45 had many encounters with the stormtime ring current. Its measurements showed that the ring-current boundary approached closest to the Earth in the evening local time sector at a distance between 3 and $5 R_{\mathrm{E}}$, depending on the strength of the disturbance. When plotted on energy-versus-time spectrograms, ring-current protons showed a nose-like structure (Smith and Hoffman, 1974). During stormtime, outbound passes, the satellite would first encounter particles with energies near $15 \mathrm{keV}$. As the satellite moved further from the Earth, it sampled fluxes of protons with both higher and lower energies. Theoretical analyses, combining Alfvén's electric-field drift with Singer's magnetic-gradient drift, were applied to simulate the motions of plasma sheet protons with different initial energies under storm-like conditions. Consistent with Dungey's model, the simulated electric field was pointed from dawn towards dusk. The results showed that the trajectories followed by plasma sheet protons conspired to produce just the spatial distribution observed by Explorer 45 (Stern, 1975; Ejiri et al., 1978). What's more, plasma sheet electrons were allowed to move closer to Earth, allowing the aurorae to move equatorward. So, end of story? Not quite. Nature still held in store surprises regarding ring-current sources, its modes of decay and relation to the Dst index. They remain topics of ongoing research.
On 26-27 January 1981 the Air Force Geophysics Laboratory sponsored a workshop whose goal was to specify the suite of particle and field sensors that should fly on the Combined Release and Radiation Effects Satellite (CRRES). Donald J. Williams, then at the NOAA Space Environment Laboratory, stunned the audience with his assessment of mass spectrometry measurements in the magnetosphere (Shelley et al., 1972). He claimed that during large magnetic storms about half the ring current's energy was carried by $\mathrm{O}^{+}$ions (Williams, 1981). To illustrate the main problem in proving this contention, Williams showed a curve representing the energy spectrum of ring-current ions over the energy range $1 \mathrm{keV}$ to $2 \mathrm{MeV}$. Existing technology allowed measurements up to about $20 \mathrm{keV}$ and above $0.5 \mathrm{MeV}$. The critical middle energy range was terra incognita.

The Charge Composition Explorer (CCE), a part of the Active Magnetospheric Particle Tracer Explorer (AMPTE) mission, in August 1984 carried a new ion mass spectrometer that utilized time-of-flight technology to sample energy per charge up to $300 \mathrm{keV} \mathrm{q}^{-1}$ (Gloeckler et al., 1985). Later studies would show that the fraction of $\mathrm{O}^{+}$constitutes $\sim 6 \%$ of the quiet-time ring current and rises dramatically during storms (Daglis et al., 1993), becoming the dominant species during large storms (Daglis et al., 1999b). Since $\mathrm{O}^{+}$is not found in the solar wind, the ionosphere must be a major source for the stormtime ring current. How $\mathrm{O}^{+}$is accelerated from $0.1 \mathrm{eV}$ in the ionosphere to tens to hundreds of $\mathrm{keV}$ in the magnetosphere remains a subject of continuing investigation. An ionospheric source for the ring current was unimaginable to both pre- and early post-Sputnik investigators.

As mentioned above, Dessler and Parker (1959) were first to suggest that energetic ions are lost to the ring current via charge exchange with low-energy hydrogen atoms in the geocorona. When such interactions take place, energetic ions become energetic neutral atoms (ENA). No longer carrying a positive electric charge, newly born ENAs do not experience magnetic forces and fly away in the directions of motion when the charge-exchange event occurred. Lui et al. (1996) were first to identify the presence of ENAs in measurements by sensors on the Geotail satellite. In December 2005 NASA launched the IMAGE satellite into an elliptical polar orbit with an apogee of $\sim 7 R_{\mathrm{E}}$. From this vantage its sensors could look down on vast swaths of the magnetospheric equatorial plane. Its scientific payload included sensors to monitor fluxes and directions of ENAs with low $(10-500 \mathrm{eV})$, medium (1-30 keV) and high (10-500 keV) energies. Indeed these sensors successfully mapped the distributions and dynamics of the ring current from its decay products during the 5-yr IMAGE mission's lifetime. However, other loss mechanisms are also now known to operate. Intense wave activity within the ring-current environments scatters ring-current particles, causing some of them to be lost to the ionosphere. Other ring-current ions are lost when their drift paths intersect the magnetopause. Sorting out the relative contributions 
of these mechanisms to the loss of ring-current ions remains a topic pursued by computer-simulation modelers of the disturbed magnetosphere.

The Dst index was specifically created to monitor the growth and decay of an almost literally understood ring current (Sugiura, 1964; Mayaud, 1980). Akasofu and Chapman (1964) found that the ring current has a significant asymmetric distribution in the main phase, with a local-time gap. This suggested that the asymmetric ring current closes through the ionosphere. The advent of magnetometer-bearing satellites in the magnetotail revealed the strength of the previously unknown current systems. Measurements by magnetometers on Explorer 33 and 35 showed that the strength of the lobe fields increases during storms. Thus, the current flowing across the magnetotail to keep the two lobes apart must also increase. Turner et al. (2000) showed that fringe fields created by enhanced cross-tail currents also contribute $\sim 25 \%$ of Dst during the main phase of storms, but very little during the recovery phase. Iijima and Potemra (1978) identified a large-scale system of field-aligned currents called Region 1 that couples the solar wind/IMF to the polar ionosphere. During storms Region 1 currents can approach $10 \mathrm{MA}$ (mega-Amps) and produce significant north-south perturbations on the ground. A recent study by Tsyganenko and Sitov (2005) found that the symmetric ring current is the largest individual contributor to Dst only in the recovery phase. Magnetic effects of the combined tail (Turner et al., 2000) and asymmetric ring currents make the largest contributions in the main phase. Nothing is simple.

\section{Summary and conclusions}

This paper provides a brief overview of the "ring current's" conceptual development. Today the ring current is almost exclusively regarded in the context of magnetic depressions observed at the Earth's surface during magnetic storms. Historically however, its existence was first postulated by Carl Størmer to explain stormtime detections of aurorae, hundreds of kilometers equatorward of the auroral zone (Størmer, 1911). Taking his cue from Birkeland's terrella experiments where faint light emissions appeared in the equatorial plane, he showed analytically that if a ring current could produce a $300 \mathrm{nT}$ perturbation at the Earth's equatorial surface, the aurorae would migrate to the magnetic latitude of Christiania. Schmidt (1917) adapted the harmonic analysis technique introduced by Gauss to show that indeed a ring current would produce the magnetic perturbation Størmer predicted. Brüche (1930) experimentally demonstrated that the introduction of a ring of electric current in the equatorial plane of his terrella caused the locus of auroral lights to migrate equatorward. Størmer's calculations and Brüche's simulations assumed that auroral electrons came directly from the Sun and entered the Earth's magnetic field on the dayside. Energies of the auroral electrons in natural as opposed to laboratory environments were largely unknown.

Sidney Chapman and Vicenzo Ferraro made the next significant advance of the pre-space era. They postulated that magnetic storms were initiated by the arrival near the Earth of fast streams of ionized gas episodically ejected from the Sun. The oncoming ion/electron gas reflected off and compressed the Earth's magnetic field, producing signatures of sudden storm commencements and initial phases. To explain the main phase, they argued that since energetic ions could not enter the Earth's magnetic field directly on the dayside, they had to come in through a side door (Fig. 5) and move to the west thus constituting a ring of current. Although they differed on the place of entry and the species of current carriers, both Størmer and Chapman-Ferraro envisaged the ring current as made up of individual energetic particles that made large loops in the magnetic field around Earth.

Hannes Alfvén shifted thinking by pointing out that charged particles in a magnetic field with a secondary force field undergo gyro-motions around guiding centers that move on trajectories perpendicular to both the magnetic and secondary force fields. He also introduced the concept of a motional electric field that he supposed was directed dusk-todawn and allowed solar electrons and ions to cross the dayside magnetopause. Inside the magnetosphere they drifted around the Earth to form the ring current, before moving downstream with the passing solar gas. Although wrong in details, Alfvén's model turned attention away from individual particle trajectories to collective effects of plasmas in the Earth's space environment.

The discovery of a permanent supersonic solar wind with a weak interplanetary magnetic field early in the space age provided the necessary information needed to solve a large fraction of the ring-current puzzle. While the ring current was not of direct concern to James Dungey, his picture of global magnetospheric dynamics sketched in Fig. 7 opened understanding of how plasma sheet/auroral particles enter the magnetosphere through the back door, convecting toward the Earth. Analyses of ion measurements in the nightside magnetosphere pointed to the plasma sheet as a source of the ring current (Frank, 1967b). Modeling of Explorer 45 measurements pointed out the critical role of stormtime electric fields in the inner magnetosphere for transporting and energizing ring-current ions (Stern, 1975; Ejiri et al., 1978).

More than half a century into the space age, a major ringcurrent problem persists. Mass spectrometry measurements show that a large fraction of the ring current's energy is carried by $\mathrm{O}^{+}$ions that originated in the ionosphere (Williams, 1981). How these ions pass from energies of about $0.1 \mathrm{eV}$ in the ionosphere to several tens of $\mathrm{keV}$ in the ring current remains a mystery still to be resolved. 
Acknowledgements. Alv Egeland is very thankful to Jøran Moen for his practical and financial support. We are grateful to the Air Force Office of Scientific Research, for supporting the work of WJB through Task 2311SDA5 and AF contract FA8718-10-C-0001 with Boston College.

Edited by: T. Kikuchi

Reviewed by: H. Lühr and A. Brekke

\section{References}

Akasofu, S.-I. and Chapman, S.: On the asymmetric development of magnetic storm fields in low and middle latitudes, Planet. Space Sci., 12, 607-626, 1964.

Allen, J.: The detection of single positive ions, electrons and photons by a secondary electron multiplier, Phys. Rev., 55, 966-971, 1939.

Bame, S. J., Asbridge, J. R., Felthauser, H. E., Olson, R. A., and Strong, I. B.: Electrons in the plasma sheet of the earth's magnetic tail, Phys. Rev. Lett., 16, 138-142, 1966.

Birkeland, Kr.: The Norwegian Aurora Polaris Expedition 19021903, Vol. 1, Sect. 1, Aschehoug, Christiania, 1908.

Brundtland, T.: The Laboratory Work of Kristian Birkeland, Troms $\varnothing$ University Rept., 1997.

Brüche, E.: Experimente zu Störmers Polarlichttheorie, Z. Phys., 31, 1011-1015, 1930.

Chapman, S.: An outline of a theory of magnetic storms, Proc. Roy. Soc. Lond. A, 95, 61-83, 1919.

Chapman, S. and Ferraro, V. C. A.: A new theory of magnetic storms, I, The initial phase, J. Geophys. Res., 36, 77-97 and 171186, 1931.

Chapman, S. and Ferraro, V. C. A.: A new theory of magnetic storms, I, The initial phase (continued), J. Geophys. Res., 37, 147-156 and 421-429, 1932.

Chapman, S. and Ferraro, V. C. A.: A new theory of magnetic storms, II, The main phase, J. Geophys. Res., 38, 79-96, 1933.

Coleman, P. J., Davis, L., and Sonnett, C. P.: Steady component of the interplanetary magnetic field, Phys. Rev. Lett., 5, 43-46, 1960.

Daglis, I. A., Sarris, E. T., and Wilkins, B.: AMPTE/CCE CHEM observations of the ion populations at geosynchronous altitudes, Ann. Geophys., 11, 685-696, 1993.

Daglis, I. A., Thorne, R. M., Baumjohann, W., and Orsini, S.: The terrestrial ring current: origin, formation and decay, Rev. Geophys., 37, 407-438, 1999a.

Daglis, I. A., Kasotakis, G., Sarris, E. T., Kamide, Y., Livi, S., and Wilkins, B.: Variations of the ion composition during an intense magnetic storm and their consequences, Phys. Chem. Earth, 24, 229-232, 1999b.

Dessler, A. J. and Parker, E. N.: Hydromagnetic theory of magnetic storms, J. Geophys. Res., 64, 2239-2259, 1959.

Dungey, J. W.: Interplanetary magnetic field and the auroral zone, Phys. Rev. Lett., 6, 47-48, 1961.

Ejiri, M., Hoffman, R. A., and Smith, P. H.: The convection electric field model for the magnetosphere based on Explorer 45 observations, J. Geophys. Res., 83, 4811-4815, 1978.

Ferraro, V. C.: A Birth of a Theory, in: Sydney Chapman, eighty, from his Friends, edited by: Akasofu, S.-I., Fogle, B., and Haurwitz, B., published privately, 1970.
Frank, L. A.: Several observations of low-energy protons and electrons in the earth's magnetosphere with OGO 3, J. Geophys. Res., 72, 1905-1916, 1967a.

Frank, L. A.: On the extraterrestrial ring current during geomagnetic storms, J. Geophys. Res., 72, 3753-3767, 1967b.

Frank, L. A.: Relationship of the plasma sheet, ring current, trapping boundary and plasmapause, J. Geophys. Res., 76, 3612-3643, 1971.

Fritz, H.: Das Polarlicht, F. A. Brockhaus, Leipzig, 1881.

Gauss, C. F.: Allgemeine Theorie des Erdmagnetismus, in: Resultate aus den Beobachtungen des magnetischen Vereins im Jahre 1838, edited by: Gauss, C. F. and Weber, W., Leipzig, 1-57, 1839.

Gloeckler, G., Wilken, B., Stüdemann, W., Ipavich, F. M., Hovestadt, D., Hamilton, D. C., and Kremser, G.: First composition measurement of the bulk of the storm time ring current (1 to $300 \mathrm{keV} / \mathrm{e}$ ) AMPTE/CCE, Geophys. Res. Lett., 12, 325-328, 1985.

Gold, T.: Motions in the magnetosphere of the Earth, J. Geophys. Res., 64, 1219-1224, 1959.

Graham, G.: An Account of Observations Made of the Variation of the Horizontal Needle at London, in the Latter Part of the Year 1722, and Beginning of 1723, Phil. Trans., 33, 96-107, doi:10.1098/rstl.1724.0020, 1724.

Graham, G.: Some Observations, Made during the Last Three Years, of the Quantity of the Variation of the Magnetic Horizontal Needle to the Westward, Phil. Trans., 45, 279-280, doi:10.1098/rstl.1748.0030, 1748 .

Halley, E.: An account of the cause of the change of the variation of the magnetic needle; with an hypothesis of the structure of the internal parts of the earth, Philos. Trans. Roy. Soc. London, 16, 563-578, doi:10.1098/rstl.1686.0107, 1692.

Hughes, W. J.: The magnetopause, magnetotail and magnetic reconnection, in: Introduction to Space Physics, edited by: Kivelson, M. G. and Russell, C. T., Cambridge University Press, New York, 242-246, 1995.

Iijima, T. and Potemra, T. A.: Large scale characteristics of filedaligned currents associated with substorms, J. Geophys. Res., 83, 599-615, 1978.

Iyemori, T.: Stormtime magnetospheric currents inferred from midlatitude field variations, J. Geomag. Geoelectr., 42, 1249-1265, 1990.

Kertz, W.: Ein neues Mass für die Feldstärke des erdmagnetischen äquatorialen Ringstroms, Abh. Akad. Wiss., Göttingen, Math. Phys., Beitr. zum Internat. Geophys. Jahr, 2, 1-83, 1958.

Kertz, W.: Ring current variations during the IGY, Ann. Int. Geophys. Year, 35, 49-51, 1964.

Lindemann, F. A.: Note on the theory of magnetic storms, Philos. Mag., 38, 669-684, 1919.

Lui, A. T. Y., Williams, D. J., Roelof, E. C., McEntire, R. W., and Mitchell, D. G.: First composition measurements of energetic neutral atoms, Geophys. Res. Lett., 23, 2642-2644, 1996.

Mayaud, P. N.: Derivation, meaning and use of geomagnetic indices, Amer. Geophys. U., Geophys. Monograph., 22, 115-129, 1980.

Nagata, T.: Development of a magnetic storm. The southward shifting of the auroral zone, J. Geophys. Res., 55, 127-142, 1950.

Ness, N. F.: The Earth's magnetic tail, J. Geophys. Res., 70, 29893005, 1965. 
Ness, N. F., Behannon, K. W., Cantarano, S. C., and Searce, C. S.: Observations of the Earth's magnetic tail and neutral sheet at 510,000 kilometers by Explorer 33, J. Geophys. Res., 72, 927933, 1967.

Neugebauer, M. and Snyder, C. W.: Mariner 2 observations of the solar wind. 1. Average properties, J. Geophys. Res., 71, 44694484, 1966.

Parker, E. N.: Extension of the solar corona into interplanetary space, J. Geophys. Res., 64, 1675-1681, 1959.

Röstadt, A.: Über die Einwirkung magnetischer Perturbationen auf die geografische Verteilung des Nordlichts, Geofys. Publ., 5, 121, 1928.

Schmidt, A.: Erdmagnetismus; Über die Ursache der magnetischen Stürme, in: Enzyklopädie d. Math. Wiss., 266-396, 1917.

Sckopke, N.: A general relation between the energy of trapped particles and the disturbance field near Earth, J. Geophys. Res., 71, 3125-3130, 1966.

Shatten, K. H. and Wilcox, J. M.: Response of the geomagnetic index Kp to the interplanetary magnetic field, J. Geophys. Res., 72, 5185-5191, 1967.

Shelley, E. G., Johnson, R. G., and Sharp, R. D.: Satellite measurements of heavy ions during a geomagnetic storm, J. Geophys. Res., 77, 6104-6110, 1972.

Singer, S. F.: A new model of magnetic storms and aurorae, EOS (Trans. AGU), 38, 175-190, 1957.

Smith, E. J.: Theoretical and experimental aspects of ring currents, in: Space Science, edited by: LeGalley, D., John Wiley, New York, 316-373, 1963.

Smith, P. H. and Hoffman, R. A.: Direct observations in the dusk hours of the characteristics of the storm time ring current particles during the beginning of magnetic storms, J. Geophys. Res., 79, 966-971, 1974.

Snyder, C. W. and Neugebauer, M.: Interplanetary solar wind measurements by Mariner 2, Space Res., 4, 89-113, 1964.

Stern, D. P.: The motion of a proton in the equatorial magnetosphere, J. Geophys. Res., 80, 595-599, 1975.
Stern, D. P.: A historical introduction to the ring current, in: The Inner Magnetosphere: Physics and Modeling, Geophys. Monogr. Ser., 155, Amer. Geophys. U., 1-8, 2005.

Størmer, C.: Sur le mouvement d'un point matèriel portant une charge d'èlectricitè sous l'action d'un aimant èlèmentaire, VSK Skr., Mat. Nat. Kl., 3, 1-32, 1904.

Størmer, C.: Sur les trajectoires des corpuscules électrisés dans l'espace sous l'actions du magnétisme terrestre avec application aux aurores boréales, seconde memoire, Arch. Sci. Phys. et Nat., Ser. 4, 32, 117-123, 190-219, 277-314, 415-436, and 501-509, 1911.

Størmer, C.: Sur les trajectories des corpuscules électrisés dans l'espace sous l'actions du magnétisme terrestre avec application aux aurores boréales, seconde memoire (continued), Arch. Sci. Phys. Nat., Ser. 4, 33, 51-69 and 113-150, 1912.

Størmer, C.: The Polar Aurora, Oxford University Press, London, 1955.

Sugiura, M.: Hourly values of equatorial Dst for the IGY, Ann. Int. Geophys. Year, 35, 945-51, 1964.

Tsyganenko, N. A. and Sitov, M. I.: Modeling the dynamics of the inner magnetosphere during strong geomagnetic storms, J. Geophys. Res., 110, A03208, doi:10.1029/2004JA010798, 2005.

Turner, N. E., Baker, D. N., Pulkkinen, T. I., and McPherron, R. L.: Evaluation of the tail current contribution to Dst, J. Geophys. Res., 105, 5431-5439, doi:10.1029/1999JA000248, 2000.

Van Allen, J. and Frank, L. A.: Survey of the radiation around the earth to a radial distance of $107,400 \mathrm{~km}$, Nature, 183, 430-434, 1959.

Vasyliunas, V. M.: A Survey of Low-Energy Electrons in the evening sector of the magnetosphere with OGO 1 and OGO 3, J. Geophys. Res., 73, 2839-2884, 1968.

Wanliss, J. A. and Showalter, K. M.: High-resolution global storm index: Dst versus Sym H, J. Geophys. Res., 111, A02202, doi:10.1029/2005JA011034, 2006.

Williams, D. J.: Ring current composition and sources: An update, Planet. Sp. Sci., 29, 1195-1203, 1981. 